\title{
SATURACIÓN DEL ESPACIO EN APOCOLOCYNTOSIS DE SÉNECA
}

\author{
Martin Pozzi \\ Universidad de Buenos Aires, Argentina \\ marpozzi@gmail.com
}

\begin{abstract}
Resumen:
El objetivo del presente trabajo es analizar y caracterizar las formas y modalidades de una serie de operaciones sobre el espacio tanto físico como simbólico presentado en Apocolocyntosis de Séneca. Dichas operaciones implican tanto el establecimiento de lugares puntuales de Roma cuanto los recorridos, pasajes y mediaciones que estos presuponen para un sujeto que se desplaza en aquellos espacios. Nuestra hipótesis es que este texto se apoya en la sobresaturación de dichas operaciones para concentrar y condensar en la percepción del receptor la ex-centricidad del emperador respecto de la urbs como centro cultural, político, geográfico y simbólico. Palabras clave: Séneca, Apocolocyntosis, Espacio, Roma, Claudio.
\end{abstract}

\section{ABstRACT:}

The aim of this paper is to analyze and characterize the forms and modalities of a series of operations on both physical and symbolic space presented in Seneca's Apocolocyntosis. These operations involve both the establishment of specific places in Rome and the paths, passages and mediations that these presuppose for a subject moving along. Our hypothesis is that this text uses the oversaturation of these operations to condense in the reader's perception the ex-centricity of the emperor with respect to the urbs as a cultural, political, geographical and symbolic center.

KeYwORDS: Seneca, Apocolocyntosis, Space, Rome, Claudius.

Es casi una verdad de Perogrullo que toda narración necesita un espacio donde desarrollarse a la vez que el tiempo transcurre: implícita o explícitamente los hechos se suceden en un devenir temporal pero también espacial, el famoso cronotopo bajtiniano. ${ }^{1}$ Se narra lo que sucede en un lugar, porque parecería imposible prescindir de un soporte material (real o ficticio) donde apoyar los hechos. ${ }^{2}$ Desde ya que estos espacios narrados no se configuran de forma autónoma u objetiva a la manera de una mera transposición especular de la realidad al texto, sino que toman entidad a partir de distintas mediaciones de la interfaz comunicativa: no son iguales el espacio realista y el maravilloso, dado que se construyen a partir de presupuestos epistemológicos distintos e implican contratatos de lectura también diferentes. La misma divergencia existe a nivel genérico, pues no se presentan a partir de los mismos componentes el espacio de la épica, de la lírica o el de la elegía, ${ }^{3}$ por nombrar los más extremos.

En tanto componente de las formaciones ideológicas, el espacio narrado se vuelve un punto pregnante en la lectura de cualquier texto porque concentra en su formulación haces significantes y simbólicos tanto directos como preconstruidos ${ }^{4}$ que en conjunto develan tramas sociales, políticas e históricas que merecen ser exploradas. Este espacio "cultural" debe ser visto entonces como un constructo social dinámico y de múltiples niveles sujeto a una continua negociación de significados por parte de sus diversos actores. ${ }^{5}$ Dentro de este esquema conceptual es preciso tener en cuenta la temprana formulación de Michel de Certeau, ${ }^{6}$ quien hace una importante distinción entre las nociones de 'lugar' y de 'espacio' a partir del estatismo de uno y la dinamización del otro: un lugar narrado cuando es el escenario de prácticas concretas -ideológicas, históricas, literarias, individuales, etc. deviene espacio. ${ }^{7}$ Una calle cualquiera es simplemente un lugar, pero se vuelve espacio en tanto es presentada como el territorio de enfrentamientos sociales, económicos, políticos,

Recepción: 30 de marzo de 2018 | Aprobación: 30 de marzo de 2018 | Publicación: 05 de septiembre de 2019 
en definitiva, un espacio cuyo significado está en permanente negociación. Otro punto merece clarificación: la calle como lugar puede existir o no, lo que nos importa, al menos en el análisis literario, va a ser ese espacio denominado "calle", su configuración, sus alternancias, los actores sociales que la atraviesan, las nociones que se presuponen, etc. Nos tiene sin cuidado dónde está y si refleja con precisión los detalles puntuales que esta tiene en la realidad concreta.

A partir de lo reseñado, pensamos que este esquema de análisis puede resultar fructífero aplicado a la Apocolocyntosis de Séneca. Esta sátira ¿̇menipea? ${ }^{8}$ sobre la supuesta apoteosis del emperador Claudio puede ser leída también como un catálogo exhaustivo de operaciones sobre el espacio, tanto físico como simbólico. Comienza con un narrador que cuenta los últimos momentos de la vida del emperador Claudio, su muerte y el regocijo que produce en todos esta noticia y el ascenso al poder de su sucesor Nerón. Como es habitual, Claudio asciende al Olimpo pero no es reconocido debido a su cojera y su tartamudez, aunque finalmente es recibido entre los dioses, quienes discuten si debe ser aceptado entre ellos. Jano mociona a favor mientras que Augusto en un encendido discurso pide su condena y expulsión inmediata. En un nuevo movimiento, Claudio es enviado a los infiernos y atraviesa su propio funeral. En este nuevo espacio se encuentra con todas sus víctimas y es condenado por el juez Eaco, aunque finalmente es pedido como esclavo por Calígula.

Así, encontramos no solo lugares puntuales de Roma, sino también recorridos, pasajes y mediaciones que estos presuponen para un sujeto que se desplaza tanto por el espacio concreto como por el narrado. En otra oportunidad ${ }^{9}$ hemos analizado la particular configuración simbólica de una serie de espacios como el lugar de nacimiento de Claudio, la confusión de límites fronterizos, la entrega de nacionalidad a pueblos apartados y las diferencias entre el cielo y la tierra. Aquí intentaremos abordar, en particular, las operaciones de vectorización del espacio por entender que estas configuran una forma más de atacar y despreciar al malogrado emperador muerto. Ya no se trata solamente de la deshumanización progresiva que Claudio enfrenta (recordemos que se lo apoda "quasi homo" ${ }^{10}$ ) sino que también el orden y la dirección de sus movimientos pueden ser leídos, tal es nuestra hipótesis, como formas también de vituperación.

Como antes mencionamos la transformación de un lugar en un espacio implica la presencia de un sujeto que allí se inscribe, de una mirada que le da entidad. Casi de forma idealista un lugar no mirado y no practicado es un lugar que no existe. De allí que nos importe no sólo la presencia de sujetos en el espacio sino también sus movimientos y su direccionalidad. ${ }^{11}$ Es claro que las conexiones entre lugares son importantes, pero más importante es ver cuál es la dirección que los sujetos establecen en ellas. En tanto cultura muy propensa a los límites, a las murallas y a las fronteras, ${ }^{12}$ no es lo mismo ir a Roma que irse de Roma, por ejemplo. En este sentido, la Apocolocyntosis a pesar de su brevedad nos presenta una gran cantidad de movimientos y direcciones. Nuestro narrador está constantemente cambiando de lugar, y, lo que nos interesa recalcar aquí, y que es el centro de nuestro análisis, es que no siempre se marca el movimiento necesario para el pasaje de un espacio a otro. Podríamos decir que hay itinerarios implícitos y explícitos. Esto no debería llamar la atención, pues no es de ninguna manera un requisito narrativo que siempre se expliciten los movimientos, pero creemos que hay una razón especial y deliberada en la elección de uno u otro procedimiento, pues como antes dijimos, no va a ser lo mismo ascender al cielo que ser echado a patadas de él. Creemos que narrar con detalle el itinerario del exilio y de la salida fracasada añade patetismo y desprecio al sujeto que lo experimentó. No es lo mismo narrar la victoria que ensañarse con la derrota: y eso es lo que hace el narrador satírico con Claudio: mostrar de todas las formas posibles la degradación ${ }^{13}$ de un individuo en todos los aspectos, morales, físicos, fisiológicos, sexuales, incluso, como es el caso presente, en su derrotero espacial.

Para mostrar esto elegimos analizar por separado la vectorialidad espacial vertical (movimiento tierra / cielo / infierno) y la horizontal (distanciamiento del centro) sin dejar de notar que estos procedimientos se dan en simultáneo, aunque por necesidad metodológica los aislamos. A partir de la analogía que hace de Certeau ${ }^{14}$ entre el movimiento en el espacio y las figuras del discurso (específicamente la metonimia y el asíndeton), analizaremos también en ambos ejes la presencia o ausencia de un itinerario manifiesto. 


\section{ITINERARIO VERTICAL}

Ya desde el inicio el narrador nos informa que narrará los hechos acontecidos en el cielo luego de la muerte de Claudio, situación que es dilatada pues se inicia el relato con los últimos momentos de la vida del emperador. Es interesante notar que prácticamente sin solución de continuidad pasamos de la tierra al cielo en un mismo tramo narrativo, como si no fuera importante ni necesario establecer un pasaje entre estos dos espacios tan diversos:

Exspiravit autem dum comoedos audit [...] Quae in terris postea sint acta, supervacuum est referre. Scitis enim optime, [...] In caelo quae acta sint, audite [...] Nuntiatur Iovi venisse quendam bonae staturae, bene canum [...]. (4-5) $)^{15}$

Pues murió mientras escuchaba a unos comediantes [...] Es inútil referir lo que ocurrió después en la tierra. En efecto, lo saben perfectamente [...] Escuchen lo que ocurrió en el cielo [...] Se anuncia a Júpiter que llegó alguien de buena estatura, bien canoso $[\ldots .$.

Vemos en este breve pasaje que entre los dos polos extremos terra / caelum no media ninguna transición ni itinerario: el pasaje de uno a otro se produce de forma implícita, como si el traslado hacia el cielo fuera una acción automática. Como antes se dijo, esta mediación implícita no representa ningún problema desde el punto de vista del hilo narrativo, dado que con precisar los dos polos ("in terris" / "in caelo") queda claro que el traslado se ha realizado, y de ningún modo es necesario indicar cómo se ha desarrollado el pasaje. Pensemos que en la economía del relato sería imposible describir y aclarar cada uno de los movimientos específicos que realizan los personajes, como los experimentos del objetivismo francés. Por el momento, nos interesa marcar esta operación como asindética, ${ }^{16}$ es decir, en definitiva, una reducción del espacio que se ve yuxtapuesto sin conexiones. Esto contrasta notablemente con el momento en que, tras la decisión de los dioses en asamblea de no aceptar la divinización de Claudio, este es expulsado inmediatamente del cielo hacia el infierno:

[...] eumque quam primum exportari et caelo intra triginta dies excedere, Olympo intra diem tertium." [...] Nec mora Cyllenius illum collo obtorto trahit ad inferos a caelo unde negant redire quemquam. (11)

que sea deportado cuanto antes y que en el plazo de treinta días salga del cielo, en tres del Olimpo [...] Y sin demora el

Cilenio, tomándolo del cuello, lo arrastra a los infiernos desde el cielo, de donde dicen que no vuelve nadie.

En notable contraste con el ascenso al cielo, donde sólo se anunciaba su llegada pero no se señalaban los pasos intermedios, tanto la sentencia de Augusto cuanto el descenso en sí están saturados de movimientos y espacios concretos: exportari, excedere, que a partir del prefijo ex-connotan el alejamiento y el movimiento 'desde'; la frase "a caelo", el relativo unde, saturando la misma noción, los verbos trabit y redire, etc. Como se puede notar, a la violencia de la situación (es expulsado, deportado y arrastrado del cuello) se le agrega la sobreespecificada direccionalidad ablativa: queda claro que el lugar de Claudio no es el cielo, y de allí debe moverse sin pausa. No es gratuita tampoco en este isotopía espacial la cita ${ }^{17}$ de Catulo (Cat. III.12), de que el infierno es un lugar "desde donde nadie puede volver". En aquel poema era un pajarito muerto el que no volvería de las tinieblas, aquí, mutatis mutandis, es un emperador de poca monta el que debe partir para allí y garantizar que nunca vuelva. Más allá del chiste (y recordemos las no pocas interpretaciones obscenas del pajarito) ${ }^{18}$ se pone un marcado énfasis en la direccionalidad del movimiento: hacia allí se va y de allí no se vuelve.

En el progresivo descenso desde los cielos, bajando por la Vía Appia, pasan por la tierra, donde se está realizando el cortejo fúnebre de Claudio. En esta duplicidad de cortejos se pone en evidencia este contraste espacial donde el emperador aparece mágicamente en dos lugares al mismo tiempo: en el eje vertical está bajando del cielo, en el eje horizontal permanece en su pompa fúnebre. Claramente en la tierra ya no tiene nada que hacer, es un sujeto pasivo (en definitiva está muerto), y la única actividad que le queda es el itinerario hacia abajo expulsado del cielo. El paso del cielo a la tierra fue bien específico y profusamente notado, en la tierra simplemente observa su propio funeral, descubre su propia muerte, se emociona con las alabanzas que un coro le entona, pero es rápidamente arrastrado a continuar el descenso. En forma previsible, y análogo al 
primer tramo desde el cielo a la tierra, el trayecto hacia el infierno nuevamente estará plagado de referencias vectoriales, sobre todo a partir de las preposiciones per para el trayecto, y ad para el destino:

\begin{abstract}
Inicit illi manum Talthybius deorum [nuntius] et trahit capite obvoluto, ne quis eum possit agnoscere, per campum Martium, et inter Tiberim et viam Tectam descendit ad inferos. Antecesserat iam compendiaria Narcissus libertus ad patronum excipiendum, [...] Omnia proclivia sunt, facile descenditur. Itaque quamvis podagricus esset, momento temporis pervenit ad ianuam Ditis [...] et magna voce "Claudius" inquit "veniet." (13)

Le echa mano el Taltibio de los dioses y, con la cabeza cubierta para que no pueda reconocerlo nadie, lo arrastra por el Campo de Marte y desciende a los infiernos entre el Tíber y la vía Cubierta. Ya se había adelantado por un atajo el liberto Narciso para recibir a su patrono. [...] Todo es cuesta abajo, se desciende fácilmente. Y así, aunque tenía gota, llega enseguida a la puerta de Dite [...] y en alta voz dice "ya llega Claudio".
\end{abstract}

Otra vez encontramos al pobre Claudio arrastrado (trahit) hacia abajo, donde se marca el itinerario a través del Campo de Marte, el Tíber y la puerta Cubierta, todos lugares de referencia ${ }^{19}$ en Roma e identificables con facilidad por cualquier receptor contemporáneo, hacia la puerta de Plutón. Con la ayuda de su fiel liberto se anuncia su llegada, y volvemos a encontrar una saturación de términos vinculados con la dirección: proclivia, descenditur, perveniet, compendiaria, venit, etc. Queda claro otra vez que Claudio ha pasado por todos los movimientos necesarios para descender desde el cielo al infierno. Es más, si pensamos en la economía del relato, el texto elige focalizar en el itinerario precisamente para crear una unidad narrativa. Sin lugar a dudas podríamos quedarnos con tres núcleos espaciales centrales: la asamblea de los dioses en el cielo, el funeral en la tierra, y el juicio en el infierno, pero el autor ha agregado una transición cargada de significados al convertir en narración un pasaje espacial que podría haber dejado implícito.

A partir de lo antedicho podemos ver que la vectorización vertical del espacio conlleva dos movimientos antitéticos, en primer lugar el ascenso desde la tierra hasta el cielo, y luego el descenso desde el cielo hacia el infierno pasando por la tierra. Más allá de la lógica y previsible diferencia entre estos dos movimientos, difieren notablemente en la forma en que han sido construidos estos trayectos desde lo narrativo. El ascenso es implícito, casi inmediato: Claudio muere y aparece en el cielo, no hay rastros de su itinerario: es asindético, sin nexos, sin mediaciones. En forma inversa, el descenso es largo, pleno de meandros y completamente explícito: catalogamos verbos, preposiciones, lugares, detenciones que saturan sus movimientos desde la expulsión. El procedimiento sirve para mostrar con toda malicia el derrotero de alguien que ha sido expulsado del cielo y lleva su fracaso a cuestas, casi como una ceremonia triunfal pero invertida. Por contraposición esta vectorización es articulada, sindética: quedan bien claros los pasos que se han seguido para pasar de un lugar a otro.

En forma paralela se desarrolla una construcción equipolente en la dirección horizontal, que pasamos a analizar ahora.

\title{
ITINERARIO HORIZONTAL
}

Así como se eligió mostrar el camino del descenso en la verticalidad, en el espacio horizontal lo que va a primar es la explicitación del valor simbólico negativo que tiene la distancia y la lejanía medidas desde Roma. El pasaje es muy interesante porque aúna varios preconstruido ${ }^{20}$ vinculados con el valor de la ciudadanía, la historia literaria y la tradición cultural grecolatina. Varios son los elementos a analizar. Ante la llegada de Claudio al cielo, y ante el desconcierto de todos por su aspecto asaz ridículo, se apela al héroe multicultural por excelencia, Hércules:

Tum Iuppiter Herculem, qui totum orbem terrarum pererraverat et nosse videbatur omnes nationes, iubet ire et explorare quorum hominum esset. [...] Diligentius intuenti visus est quasi homo. Accessit itaque et quod facillimum fuit Graeculo,

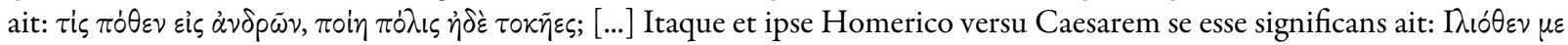

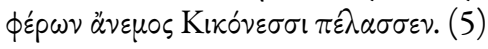


Entonces Júpiter ordena a Hércules, que había recorrido todo el mundo y parecía conocer todas las naciones, que vaya y averigüe de qué pueblo es [...] Al mirarlo con más detenimiento le pareció casi un hombre. Se acercó entonces y, lo que es muy fácil para un grieguito, le dice: ¿quién eres, de qué país vienes? ¿En dónde están tu ciudad y tus padres? [...] Y para dar a entender que es un César, dice también con un verso homérico: “desde Troya junto a los cícones ha ido llevándome el viento”.

Aquí notamos otro aspecto interesante del espacio, casi podríamos decir, literaturizado. Se utilizan versos homéricos (quién mejor para hablar de viajes, trayectos, desarraigo y errancia) tanto para preguntar cuanto para responder. El efecto que se logra es doble, en primer lugar la parodia y descontextualización del texto homérico sirve tanto para menoscabar la autoridad tanto de Hércules como de Claudio. Recordemos que, más allá de su perfil heroico, el primero se construye en el texto como compañero y lobbista del emperador; se lo predica como tonto, despreciativamente como "grieguito" y fácilmente engañable. Por esta razón no tiene discurso propio y debe utilizar una fórmula homérica. Claudio, por lo demás, además de tonto es mentiroso, pues claramente no es troyano ni estuvo siquiera cerca de ninguna guerra ni campaña militar. En segundo lugar, se pone en evidencia la irrealidad tanto de los enunciados como de la pretensión claudiana. Estos espacios positivamente connotados (pensemos que Troya es prácticamente la cuna simbólica de Roma) no pueden ingresar al texto más que en un segundo grado, como una cita intertextual, y reforzando su carácter literario: no puede quedar ni la menor posibilidad de sugerir una eventual capacidad épica de Claudio. El texto recupera una dimensión metaliteraria, casi una puesta en abismo para subrayar la propia artificiosidad de estos espacios pretendidos. La referencia a Troya debe quedar para Homero, y casi como un juego, pero bien lejos de Claudio.

Pero si quedaban dudas, se las expele rápidamente con la intervención de la diosa Fiebre:

Et imposuerat Herculi minime vafro, nisi fuisset illic Febris, quae fano suo relicto sola cum illo venerat: ceteros omnes deos Romae reliquerat. "Iste" inquit "mera mendacia narrat. Ego tibi dico, quae cum illo tot annis vixi: Luguduni natus est, Marci municipem vides. Quod tibi narro, ad sextum decimum lapidem natus est a Vienna, Gallus germanus. Itaque quod Gallum facere oportebat, Romam cepit. Hunc ego tibi recipio Luguduni natum, ubi Licinus multis annis regnavit. Tu autem, qui plura loca calcasti quam ullus mulio perpetuarius, [Lugudunenses] scire debes multa milia inter Xanthum et Rhodanum interesse." (6)

Y había embaucado a Hércules, que no es muy inteligente, si no hubiera estado allí la Fiebre, que había venido sola con él tras abandonar su templo: abandonó a los demás dioses en Roma. "Ese, dice, cuenta puras mentiras. Te lo digo yo que he vivido tantos años con él: nació en Lyon, estás viendo a un vecino de Marco. Lo que te digo, nació a dieciséis millas de Viena, un verdadero galo. Y como era lógico que hiciera un galo, capturó a Roma. Te lo vuelvo a decir, nació en Lyon, donde reinó muchos años Licino. Pero vos, que pisaste más lugares que un mulero a destajo, debes saber que entre el Janto y el Ródano hay muchas millas".

Aquí vemos en acción el uso del vector espacial horizontal para marcar el carácter extranjero de Claudio. A su pretensión de hacerse pasar como troyano cual Eneas fundador, se le contesta con la dura realidad de no ser más que un galo, encima de una ciudad menor. $Y$ es preciso tener en cuenta la formulación de estos itinerarios nuevamente explícitos. La diosa Fiebre le reitera una y otra vez "es ciudadano de Lyon", incluso con un término poco adecuado a su rango imperial como "municipem" ("habitante de un municipio ${ }^{21}$ ). Por si esto fuera poco, se explicita claramente la distancia de Lyon a Viena, la capital de la Galia, es decir, se avanza por medio de restricciones que van resaltando su escasa alcurnia: en primer lugar, no es troyano $(+)$ sino galo (-); y en segundo lugar, ya dentro de lo negatividad implícita en ser galo, no es vienés $(+)$ sino de Lyon $(-)$. Es decir, la pretensión épica y fundacional de un origen troyano se quiebra por la real proveniencia de la Galia. Ya dentro de esta 'negatividad', podría haber sido de la ciudad más importante, pero ni siquiera eso, es de un municipio de las afueras. En este sentido, también hay una reinterpretación de fenómenos culturales paralelos. Los troyanos y los galos no son lo mismo, en términos ideológicos. Ambos atacaron Italia, unos para fundar Roma, otros para someterlos. Unos son fundadores, otros son invasores. Por eso los troyanos son positivos (y por eso hay que evitar a toda costa que un ser abyecto como Claudio pueda siquiera aparecer como tal). Por el contrario, los galos tienen una larga historia de luchas y guerras con los romanos que finalizó con la dominación encarada por Julio César con sus famosas campañas. El desprecio hacia estos se mantuvo 
como una constante en el imaginario republicano e imperial, por lo cual no venía mal recordar el verdadero origen del emperador para continuar en la vituperación. Como bien lo explica la Fiebre: "hay mucha distancia entre el Janto (río de Troya) y el Ródano (río de Galia)”. Y lo fundamental es justamente el verbo utilizado, interesse, es decir, 'estar entre', 'mediar'. No muy distinto de lo que vimos en el plano vertical, aquí tenemos tres espacios que es preciso alejar: Troya - Roma implícitamente en el centro - Galia. No habrá en este caso un trayecto recorrido explícitamente como en el descenso, pero sí implícitamente se enfatiza la distancia y la no yuxtaposición de los espacios. Es preciso que haya distancia y que se note para dejar a Claudio como un extranjero, como un invasor que nunca tendría que haber llegado a Roma.

En la lectura propuesta vemos cómo la vectorización del espacio vertical y horizontal en conjunción con las técnicas narrativas asindética y sindética permiten reconocer esquemas simbólicos e ideológicos de una clara polaridad. El ascenso y el descenso del cielo son narrados de forma completamente distinta porque lo que interesa recalcar no es que llegó al cielo sino sobre todo que fue expulsado y debió recorrer un largo camino hasta su destino final. Aquí el núcleo positivo es el cielo (donde no debe estar Claudio) y el negativo el infierno (su lugar final): lo que se refuerza por medio de la vectorización reiterativa del espacio vertical es cuánto pasa en uno y en otro espacio. Esta cuantificación es significativa: casi nos olvidamos del ascenso, pero el descenso tortuoso permanece en nuestra mente. De forma análoga en el eje horizontal, Séneca hace todo lo posible por poner distancia, por poner "espacios que estén entre" para alejar simbólicamente al emperador del centro del mundo, es decir, Roma. ${ }^{22}$ Y en este sentido debemos traer a colación el interesante análisis que Nussbaum ${ }^{23}$ hace sobre esta obra desde la perspectiva de la risa en función filosófica. Para esta autora, Séneca en Apocolocyntosis se aparta del procedimiento estoico, que ha utilizado y utilizará en otras obras, de la risa como efecto 'terapéutico' en el receptor al reconocer la verdadera realidad de las cosas, para dar lugar a una concreta modulación del 'fastidium'. La ira manifestada tanto en el emisor satírico cuanto en prácticamente todos los personajes que interactúan con el emperador se complementa con el asco y el desprecio que rezuman los actos escatológicos ${ }^{24}$ y los movimientos asimétricos que hemos descripto. De esta manera el receptor así interpelado no sentirá empatía alguna ni por la situación ni mucho menos por Claudio, sino que el propio escarnio -a nivel fisico, moral y espacial- logrará la anulación final de la figura del emperador muerto. Y en esta trascendencia, nos dice Nussbaum, podemos encontrar un principio de acercamiento a la doctrina estoica, en tanto queda para el lector el movimiento de apartarse de estas cosas y reconocer tras una aparente grandiosidad su verdadero carácter ordinario.

Para finalizar digamos entonces que este texto se sirve tanto de la vectorialidad espacial vertical (cielo / tierra / infierno) cuanto horizontal (Roma / Lyon / Viena / Troya), y en los recorridos implícitos o explícitos de dichos itinerarios para concentrar y condensar en la percepción del receptor la ex-centricidad del emperador respecto de la urbs. Con estos procedimientos desde lo discursivo se intenta promover la idea de que Roma tuvo un emperador que estaba de paso, que no tenía un lugar concreto y que debía irse, tanto en forma física como simbólica. En definitiva, como venía ocurriendo desde la lejana fundación de Roma, todas proyecciones y operaciones sobre un espacio en permanente disputa.

\section{Notas}

1 Bajtin, M., Teoría y estética de la novela, Madrid, Taurus, 1989, 237-238: "En el cronotopo artístico literario tiene lugar la unión de los elementos espaciales y temporales en un todo inteligible y concreto. El tiempo se condensa aquí, se comprime, se convierte en visible desde el punto de vista artístico; y el espacio, a su vez, se intensifica, penetra en el movimiento del tiempo, del argumento, de la historia. Los elementos del tiempo se revelan en el espacio, y el espacio es entendido y medido a través del tiempo".

2 Un buen resumen histórico y crítico de esta problemática en J. Parker, "Conceptions of Place, Space and Narrative: Past, Present and Future”, Amsterdam international electronic journal for cultural narratology 7-8, 2012-2014. 
3 Cf. Fedeli, P., "Dalla cità dell'amore alla cità che cresce: la Roma di Properzio”, en: Pimentel, C.; Brandao, J. L.; Fedeli, P. (coords.), O poeta e a cidade no mundo romano, Coimbra, Centro de Estudos Clássicos e Humanísticos da Universidade de Coimbra, 2012, 65-82.

4 Los elementos preconstruidos son enunciados que se originan en discursos o prácticas anteriores y que, por efecto de la interpelación ideológica se encuentran en el discurso sin ser mencionados explícitamente como tales. Este efecto permite que se tomen como válidos contenidos que el discurso no demuestra. Cf. Pecheux, M., Semântica e discurso. Uma crítica à afirmação do óbvio, Campinas, Unicamp, 1988.

5 Cf. Gilhuly, K. \& Worman, N. (eds.), Space, Place, and Landscape in Ancient Greek Literature and Culture, Cambridge, Cambridge University Press, 2014, 1-2.

6 Cf. de Certeau, M., La invención de lo cotidiano. Vol. I: Artes de hacer, México, Universidad Iberoamericana, 2000, 129-130.

7 Mantenemos esta distinción por parecernos todavía pertinente la elección léxica (lugar / espacio) y la formulación de de Certeau (La invención de lo cotidiano) tomada en conjunto con los aportes de Lefebvre (The production of space, Oxford, Blackwell, 1991). En los últimos años hay quienes prefieren, no desprovistos de razón, invertir el alcance de estos términos. Cf. Gilhuly \& Worman, Space, Place and Landscape, 8-9.

8 Los debates sobre el género, el título y la autoría de esta pequeña obra no están aquietados. Entre las obras críticas imprescindibles debemos citar: Cortés Tovar, R., “Apocolocyntosis de Séneca. Estado de la cuestión”, Anuario de estudios filológicos 7, 1984, 75-93 y Teoría de la sátira. Análisis de Apocolocyntosis, Cáceres, Universidad de Extremadura, 1986; Hooley, D. M., Roman satire, Oxford, Blackwell, 2007, 141-147; Teerling, J. S., The Apocolocyntosis. The Title and Seneca's Authorship reconsidered, Lund, Lunds Universitet, 2006, y Roncali, R., “Apocolocyntosis”, en: Damschen, G.; Heil, A. (eds.), Brill's Companion to Seneca: Philosopher and Dramatist, Leiden, Boston, Brill, 2014, 673-686.

9 Cf. Nenadic, R. \& Pozzi, M., "Mi ciudad, tu ciudad (una lectura de la Apocolocyntosis de Séneca)”, Argos 23, $1999,53-59$.

10 Cf. Morton Braund, S. \& James, P., "Quasi homo: distortion and contortion in Seneca's Apocolocyntosis”, Arethusa 31.3, 1998, 285-311.

11 de Certeau, La invención de lo cotidiano, 129-130.

12 Cf. De Sanctis, G., "Solco, muro, pomerio", Mélanges de l'Ecole française de Rome. Antiquité 119.2, 2007, $503-526$. Una interesante perspectiva desde las fuentes literarias en Dench, E., Romulus' Asylum. RomanIdentities from the Age of Alexander to the Age of Hadrian, Oxford, Oxford University Press, 2005, cap. "Roman etnographies".

13 Sobre el disgusto y el desprecio hacia Claudio, cf. el estimulante análisis de Nussbaum, M., "Stoic laughter: a reading of Seneca's Apocolocyntosis”, en Bartsch, Sh.; Wray, D. (eds.), Seneca and the Self, Cambridge, Cambridge University Press, 2009, 84-112, que retomamos hacia el final de este trabajo.

14 Cf. de Certeau, La invención de lo cotidiano, 110-114.

15 Citamos por la edición de L. Annaei Senecae AПOАOKYNTSIIL. Ed. Renata Roncali, Leipzig, Teubner, 1990. Las traducciones son propias.

16 Cf. de Certeau, La invención de lo cotidiano, 113-114: "Una [i.e. la sinécdoque] dilata un elemento de espacio para hacerlo representar el papel de un "más" (una totalidad) y sustituirlo (la bicicleta o el mueble en venta tras una vitrina vale para una calle entera o para un vecindario). La otra [i.e. el asíndeton], por elisión, crea a partir de lo "menos", abre ausencias en el continuum espacial, y retiene sólo unos trozos escogidos, incluso unas reliquias. Una reemplaza las totalidades con fragmentos (un menos en vez de un más); la otra las separa al suprimir los nexos conjuntivos y consecutivos (una nada en vez de cualquier cosa). Una densifica: amplifica el detalle y miniaturiza el conjunto. La otra corta: deshace la continuidad y desmantela la realidad de su verosimilitud. El espacio así tratado y modificado por las prácticas se transforma en singularidades amplificadas y en islotes separados".

17 Cf. O’Gorman, E. “Citation and authority in Seneca's Apocolocyntosis”, en: Freudenburg, K. (ed.), The Cambridge Companion to Roman Satire, Cambridge, Cambridge University Press, 2005, 95-108.

18 Cf. una recopilación de las distintas opiniones en Haig Gaisser, J. (ed.), Oxford Readings in Catullus, Oxford, Oxford University Press, 2007, part VI “Debating the sparrow”, 305-342.

19 Lieux de référence, cf. Corbier, M., "Pallas et la statue de César. Affichage et espace public à Rome”, Revue numismatique 152, 1997, 11-40.

20 Cf. nota 4.

21 Cf. OLD, s.v. municeps.

22 Cf. Whittaker, C.R., Rome and its Frontiers: the Dynamics of Empire, London, Routledge, 2004, cap. "Mental maps and frontiers: seeing like a Roman”, 63-87.

23 Cf. Nussbaum, M., "Stoic laughter...".

24 Cf.4.3: "ultima uox eius haec inter homines audita est, cum maiorem sonitum emisisset illa parte, qua facilius loquebatur: 'uae me, puto, concacaui me.'” (Se escuchó entre los hombres su última palabra cuando emitió un fuerte sonido por aquella parte por donde más fácilmente hablaba: 'ay de mí, me cagué encima'”). 